Proceedings

\title{
Analysis of Customers' Reactions to E-Commerce Companies Using Instagram Data ${ }^{\dagger}$
}

\author{
Ekin Akkol
}

Citation: Akkol, E. Analysis of Customers' Reactions to E-Commerce Companies Using Instagram Data.

Proceedings 2021, 74, 12.

https://doi.org/10.3390/ proceedings2021074012

Published: 9 March 2021

Publisher's Note: MDPI stays neutral with regard to jurisdictional claims in published maps and institutional affiliations.

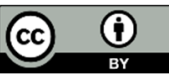

Copyright: (C) 2021 by the authors. Licensee MDPI, Basel, Switzerland. This article is an open access article distributed under the terms and conditions of the Creative Commons Attribution (CC BY) license (http://creativecommons.org/licenses/by/4.0/).

\author{
Department of Management Information Systems, Izmir Bakircay University, Izmir 35665, Turkey; \\ ekin.akkol@bakircay.edu.tr \\ + Presented at the 7th International Management Information Systems Conference, Online, \\ 9-11 December 2020.
}

\begin{abstract}
The aim of this study is to develop a web application that supports decision-making processes on subjects - such as customer relations management, marketing, and stock managementwith data such as posts, comments, and likes from Instagram to four e-commerce companies. In this context, the data obtained from the Instagram accounts of e-commerce companies were recorded in a database after the pre-processing and classification stages. A web application has been developed that can support managers in their decision-making processes at operational, tactical, and strategic decision-making levels by visualizing the data recorded in the database.
\end{abstract}

Keywords: social media analysis; web application; sentiment analysis; customer relationship management; emoji

\section{Introduction}

Today, with the development of internet technologies, the use of platforms such as social media is increasing. Consumers stay in touch with other users and establish an interactive communication through social media platforms. Before or after purchasing a product or service, consumers who exchange ideas with other consumers and their contacts in online communities and social networks can be influenced by comments and posts to differentiate their purchasing decisions. There are many opportunities and threats for companies in the social media environment, where all kinds of positive and negative information about them and their products can be disseminated rapidly, and most of them are beyond the control of companies.

Everyday, consumers who are increasingly bringing the internet and social media into their daily routines produce useful data ready to be analyzed for companies, particularly on social media platforms. Social media helps companies to obtain data from an audience that cannot be accessed by a conventional data collecting tool, a survey. The transformation of data into information will provide companies with a competitive advantage; it will also help make decision-making processes simpler and more effective. Social media, which is a contact channel where people can express their thoughts and views; it offers companies the ability to learn about their goods and services quickly from current or future consumers' opinions [1]. Customer-generated content provides a background for people to evaluate products that affect their online purchasing decisions and shopping experiences [2].

Companies, with the data obtained from social media, can seek answers to such questions as "How can we understand that customer satisfaction has decreased?", "How can we find out what our customer says about our company?", "How can we make sense of customers' complaints?", "How can we reach flexible and useful reports on brand image and customer satisfaction?". This study aims to develop a web application capable of addressing all of these questions. 
Information regarding current studies is given in the first section of this study, which consists of three parts, and the differences and similarities of the method and analysis with other studies are explained. In the second section, the methods used in the study are explained in detail. The screenshots of the created web application were shared in the third section, and details such as figures and tables were examined throughout the application, and discussions were made about what benefits it could offer to companies. The study results were discussed in the discussion section, and information was given about what can be done in future studies.

\section{Literature Review}

With the prevalence of social media, many studies are being carried out today to examine the users' desires and feelings. Most of these studies are focused on users' comments and shares on social media; they are carried out using techniques such as text mining and sentiment analysis.

Tian et al. [3] claimed that, in addition to the texts, the emojis commonly used in social media reflect the emotional state of the users and emojis should be analyzed separately. In the study where Facebook was chosen as the social media platform, the comments and reactions given to the posts under the posts of various media organizations (BBC, CNN, Le Figaro, Die WELT, etc.) from four different countries (England, America, France, and Germany) were analyzed by drawing them. In the study, 57 million reactions and 8.4 million comments were used from a total of 21000 posts. When Facebook reactions were analyzed, it was found that the "Like" reaction was used the most with $78.9 \%$, followed by "Love" (5.5\%), "Angry" (5.4\%) "Sad" (4.0\%), "Haha" (3.7\%), "Wow" (2.5\%) reactions were given. When evaluating the emojis used, it was found that users in all countries used emojis that express positive emotions more often than emojis that express negative emotions. As a result, it turns out that there is a strong correlation between emojis and reactions. The researchers concluded that this indicates that emojis can be used in emotion analysis studies.

Chen et al. [4] pointed out that textual sentiment analysis has been studied a lot in the literature on platforms such as Twitter and Instagram, but the number of studies that include emojis is very low. A model was built in this context in which emojis are also used in the study of the emotion analysis. The sentences in which the emojis are used are categorized by the emotions they represent, and the machine was taught the emoji is used in the sentences written with which emotion. In the study in which LTSM (long-term short memory) neural network architecture was used, it was observed that two-way emotion analysis using emojis performed better with higher success rates compared to other studies.

In their research, Akın and Şimşek [5] aimed to gather the audience views of a television channel on social media, to obtain useful information for the channel and to support decision-making processes. For this purpose, the Twitter messages sent about the programs on the channel between November and June 2017 were obtained using the Twitter API. The tweets collected were analyzed with the adaptive dictionary-based emotion analysis algorithm by passing through the data pre-processing stage. The analyzed tweets were examined together with the rating values of the channel and the relationship between them was tried to be determined. As a result, it has been observed that negative tweets are associated with the decrease in rating values, while positive and neutral tweets are associated with the increase in ratings. It has been mentioned within the scope of the study that channels may also base their decisions on whether or not the programs will continue to broadcast, based on social media messages. Furthermore, it was pointed out that different results can be obtained in future studies by assessing the dominant elements by analyzing the content of the messages not just in terms of emotion.

In their research, He et al. [6] emphasized that companies need to track and evaluate not only the customer-generated content on their own social networking platforms, but also text information on their competitors' social networking pages in order to improve 
competitive advantage and accurately assess the competitive environment of businesses. Three large pizza companies were chosen in this case, and messages sent to businesses via Facebook and Twitter were collected and analyzed. Incoming messages are grouped as positive, negative, and neutral and it is aimed to contribute to the decision-making processes of companies. It has also been mentioned that reviewing each other's data would contribute to the benchmarking process for businesses. The analyzes within the scope of the study were carried out using text mining methods, and the SPSS Clementine text mining tool was used for analysis. Findings from this research suggest that social media plays an important role in maintaining a positive customer relationship.

In their study, Ghiassi et al. [7]-using n-grams and statistical analysis-introduced an approach to supervised feature reduction to develop a specific Twitter lexicon for sentiment analysis. They created the Twitter specific dictionary with brand-specific terms for tweets about the brand. The dictionary created consists of 187 features. In addition, the researchers added negative and positive emojis to their studies in order to increase the success rate and achieve better analysis results. The developed dynamic artificial neural network model and support vector machines from traditional methods were compared and it was determined that the developed brand-specific system gave better results. In addition, unlike other studies, it has been observed that the use of emojis in emotion analysis increases the accuracy of the study.

By analyzing symbols called emotion tokens, including emotion symbols (e.g., emoticons and emoji ideograms) in his research, Wolny [8] focused on Twitter messages. In the study, it was mentioned that tweets are short and informal messages and the importance of emojis in emotion analysis was emphasized. Study explained how to build a emotion classification system architecture. As a result, It is thought that studies that include expressions such as emojis will yield better results.

$\mathrm{Xu}$ et al. [9] aimed to examine customer satisfaction and dissatisfaction regarding the features of hotel products and services based on online customer text reviews. In the study, using text mining and latent semantic analysis (LSA), the main features that increase customer satisfaction and dissatisfaction with hotel products and service features were determined. In addition, the effects of travel goals, hotel types, star rating, and editor's suggestions on customers' perceptions of the properties of hotel products and services were analyzed using regression analysis. As a result, four key features that increase customer satisfaction (staff, room, location, and value) and five key features that affect customer dissatisfaction were obtained (value, room, staff, facilities and facility, operational problems). In addition, the study found that among hotels with different star levels, customer satisfaction, and dissatisfaction with product and service features differ significantly.

In the light of all these studies, it has been observed that texts and emojis obtained from social media have very useful results in the scope of sentiment analysis and information extraction. It is striking that the main purpose of the studies is to test the methods and compare the success rates. Reporting the analysis to managers through dashboards, however, can lead to the emergence of useful systems that can be used in real life. As evidenced by the literature studies, the study developed in this direction was enriched with a dashboard design and focused on emojis and user reactions on social media. As a result, it is expected that the designed system will both support companies in their decision-making processes and add value to companies as a result of easily seen negative comments on customer relationship management.

\section{Materials and Methods}

Within the scope of the study, Waterfall SDLC model steps, which are frequently used in software development, were followed. Every phase comes after a phase is completed in this model, and tasks can be divided according to phases. The output of one phase becomes input of the next phase so in the next step we have the option of revisiting phases [10]. The model used in this study is shown in Figure 1. 


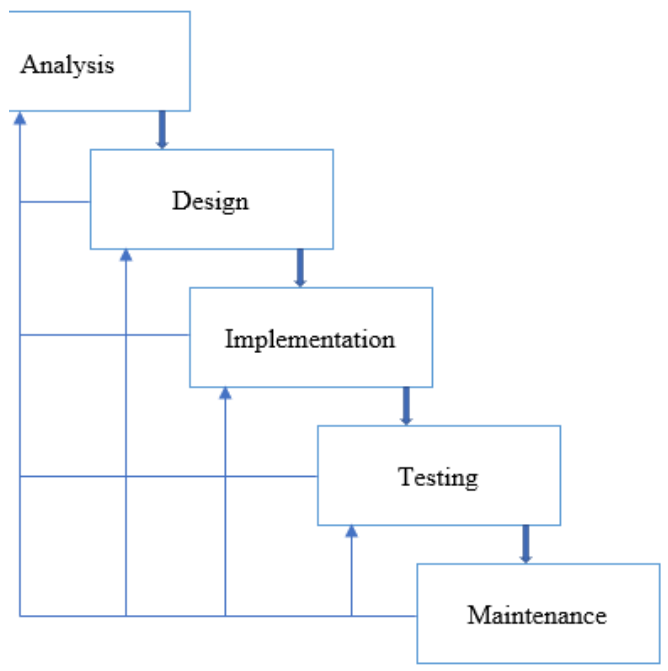

Figure 1. Waterfall model [11].

First of all, system requirements were determined. In line with the purpose of the study, what kind of information would be required has been thoroughly analyzed. Later, in the design process, it is technically designed how a software solution can meet these needs. The designed application development process is shown in Figure 2.

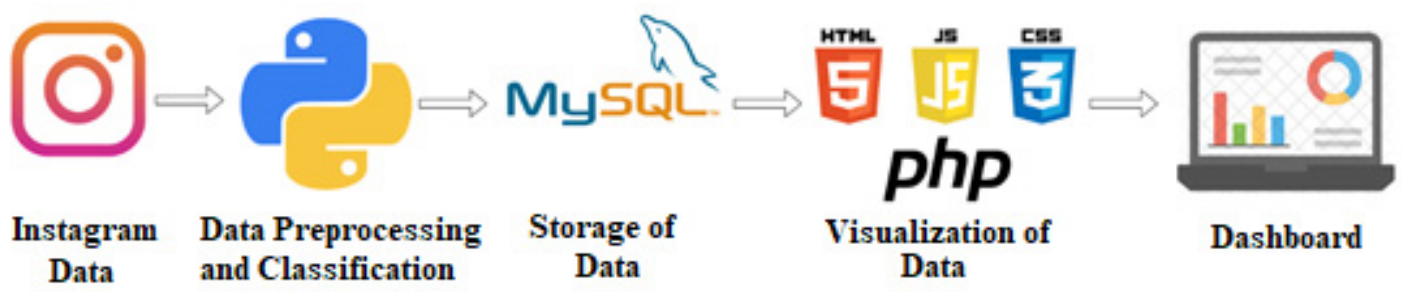

Figure 2. Application development process.

The web application was developed step by step according to this application development process. First, Instagram posts from the four leading e-commerce companies operating in Turkey, comments from posts and likes, number of followers, data such as the number of posts were taken in the csv extension using the programming language JavaScript in the application development process. At the same time, all the images of the brands selected in the categories of shoes, bags and watches and the number of likes received for those photos were collected for the title of 'marketing suggestion'.

The text data obtained using the Python programming language was subjected to various data processing and classification stages in the second and third stages of the application development process and recorded in the database. Emojis were categorized as positive, negative, and neutral for the emoji analysis conducted within the scope of the study at this stage, where the data is classified and also prepared for visualization (Figure 3). The library "emoji" was used in order to recognize emojis in the Python programming language. The emoji numbers obtained from the texts were ready to be recorded in the database as a result of the classification process. The process of classifying the emojis and counting positive, negative and neutral emojis in the database was also made for the posts of four e-commerce companies.

Figure 3. The process of categorizing emojis. 
Another process performed at this stage is word counting in order to create word cloud and word frequency tables to be displayed on the application. Before the words were counted and recorded in the database, text data was pre-processed. Both punctuation marks and emoji were removed from the data as part of the preprocessing step and a text-only file was obtained. Later, the frequency of passing words in this text file were obtained with an algorithm written using the Python programming language and made ready to be saved in the database.

At this point, in order to reveal analyzes according to the number of likes of the comments posted, the comments and the number of likes collected from Instagram accounts were filtered from the extracted data and recorded in the database. At the same time, the data of the number of photos and likes for the title of "marketing suggestion" were recorded in the database.

In the fourth stage of the application development process, PHP is used in the backend part of the web application developed to report the data recorded in the database to the managers. In the front-end part, JavaScript, HTML, and CSS are preferred.

A system was introduced in the dashboard stage, which is the last step of the application development process, to provide managers with various graphics, images, and information in a structure that can provide support for customer relationship management, marketing, and decision making. The study was conducted by collecting and analyzing user responses (comments and likes) that arrived on the Instagram pages of four e-commerce companies selected for the application. Additionally, a marketing recommendation page was created from the Instagram accounts of selected major shoe, bag and watch manufacturers with the posts and number of likes. During the design process of the application, care was taken to develop a user-friendly interface as much as possible, using simple graphics that direct the manager directly to the details instead of complex structures.

After the application development process is over, database relationships, whether the code blocks work correctly, and whether the graphics are suitable for the purpose were tested and the application was finalized.

\section{Results}

The number of comments and likes were collected from four e-commerce companies operating in Turkey selected with this study on the Instagram accounts and different analyses were made from this information. In addition to these, the study also included the posts of major shoe, bag and watch companies as well as the number of likes of these posts. Analyzes are shown on a dashboard with graphics and figures that are sufficiently easy for managers to understand for successful reporting. The developed web application is composed of five separate pages and two parts.

\subsection{E-Commerce Companies}

The study was carried out on real e-commerce companies' Instagram data and the company names were kept confidential (They were named as X Company, Y Company, Z Company, H Company). In the first part of the application, which consists of four menu titles, information about the total number of followers, the total number of posts, the total number of comments in the last 30 posts, the total number of likes in the last 30 posts, sentiment analysis of user comments according to emojis, the word cloud and list of the most used words in the comments, the most liked comments and number of likes, the most liked photo, and the most commented photo were included.

The total number of followers, the total number of posts, the total number of comments in the last 30 posts, the total number of likes in the last 30 posts indicate how much interaction companies on social media have received. Companies have the ability to see the social media activities of both their own and competitor companies based on this information. There are a total of 38 million Instagram users in Turkey, according to Digital 2020 reports [12], and so the numbers here are very critical for companies. The high 
number of likes and followers can be proof that the company is on the right track. At the same time, by analyzing the strategies of businesses with a high number of likes and followers among other companies, the company can change its social media management style.

At the sentiment analysis of user comments based on emojis and the word cloud of the most used terms in comments graphics, a pie chart shows how many positive, negative, and neutral comments the companies get on their Instagram account. In this way, companies will be able to measure customer satisfaction. In addition, by seeing the number of words used, the reasons for this satisfaction or dissatisfaction will be analyzed. With these two graphics, it is aimed to make both sentiment analysis and hidden information extraction. When looking at the graphics, users mostly comment with positive and neutral feelings, although it varies according to the company, and the words such as "product", "order", "cargo", "return", "did not come", "solution", "money", "victim" has been used. According to these words, companies have the chance to see what kind of issues customers are complaining about or satisfied with. For example, for $\mathrm{X}$ company, it is possible for the managers to comment that there may be some problems with the delivery and return of the products in general.

In the graph of the most liked comments and the number of likes, it is possible for the company to see the most supported comments among users. In this way, different policies can be developed by performing a satisfaction analysis according to the content of these comments supported by many of the customers. In addition, comments on other companies' posts can be analyzed to see more clearly what might cause customers to react or complain. One of the most important features of the system is that it allows comparison and clearly reveals the data of competitors.

Managers were enabled to see the photos with the most reactions in the most liked photo and the most commented photo section. Managers can organize various campaigns for similar products by looking at the most liked photo, use them visually in advertisements, or take similar actions. When analyzing the photos of the four e-commerce companies that received the most likes and comments, it was seen that the customers reacted more to the photos about national values, social responsibility projects and discounts. Accordingly, companies paying more attention to national days than they normally do will be a factor that will increase brand value in the eyes of customers.

The part of the web application designed within the scope of the study for X Company is shown in Figure 4. All of the pages designed for companies have a standard structure and only the data changes. 


\begin{tabular}{|c|c|}
\hline$?$ & x Company \\
\hline$\Leftrightarrow$ & Ycompany \\
\hline$\theta$ & z company \\
\hline 車 & H Company \\
\hline$\stackrel{1}{\prime}$ & Marketing Suggestion \\
\hline
\end{tabular}

\section{F x company}

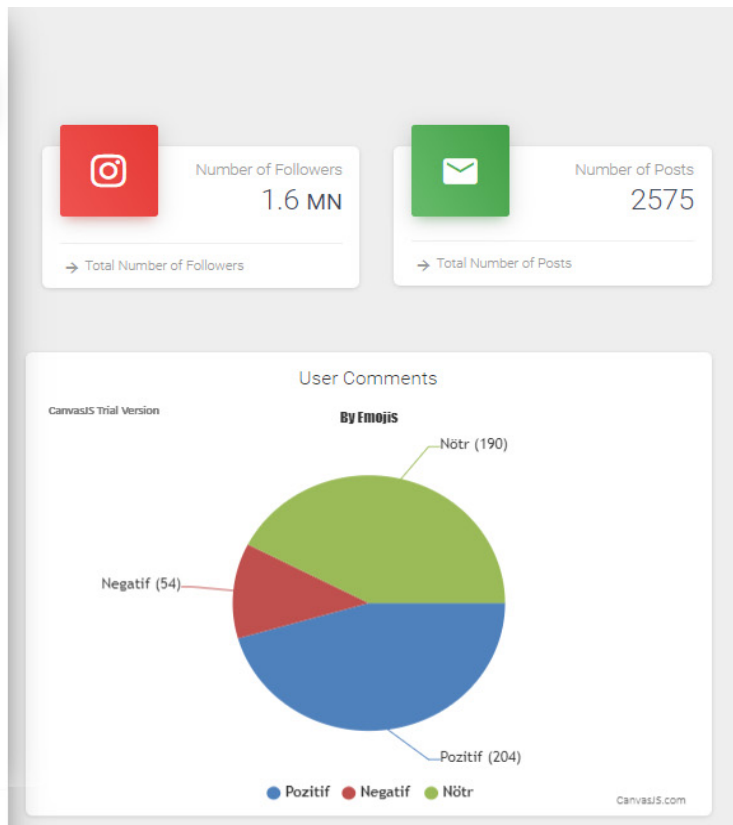

Top Rated Comments

5 comments

Comments

Number
of Likes

Güveniniz sarsliyor elestirileri okudum milyonlara hitap eden bir isim olarak o Üzücü Bir durum ligerisindesiniz

Cidden yeter ya o ürün bugün gelir yada paramı iade edersiniz yada ben bu siteyi rezil ederim ürünüm bügun geldi geldi yada paramı verin gerçekten bu

$\mathrm{Ne} \mathrm{ya} \mathrm{sizin} \mathrm{aptal} \mathrm{keyfinizi} \mathrm{bekliyemem} \mathrm{kargoyu} \mathrm{aradim} \mathrm{açmadilar} \mathrm{Ne}$ bu

boyle yeter artik yeter nefret ettim bu siteden aptal aptal Mesaj|arla cevap

veriyorsunuz bugün dördü ama ürün yok Ne zaman gelecek bu ürün

740356468 adresı bulamadigniz kargo icin 20 nisandan berı lade surecin baslatamadinız bu hirsızlik değillde ne Hep aynı otomatik mesaj|arla bilgı

veriyorlar sacma bir sirketisiniz Cevremin sizfen alisveris yapmaması ıcin

elimden gelenı yapacaŏ

Neden siparisimin faturasini kesiyorsunuz ancak kargoya vermiyorsunuz Neden neden neden

Kesinlikle alıșveris yapmayin Ellerinde olmayan ürünü satip sizi haftalarca bekletiyorlar Ben 24 nisanda alişveris yaptım Hala bir haber yok Otomotik mesaj gönderiyorlar sadece Çözüm yok Ne üünu gönderiyorlar nede iptal ediyorlar Cimere șikayet ettim Sizde şikayet edin Başka çozümu yok

\section{$\Theta_{\text {Most Liked Photo }}$}

4682 Likes

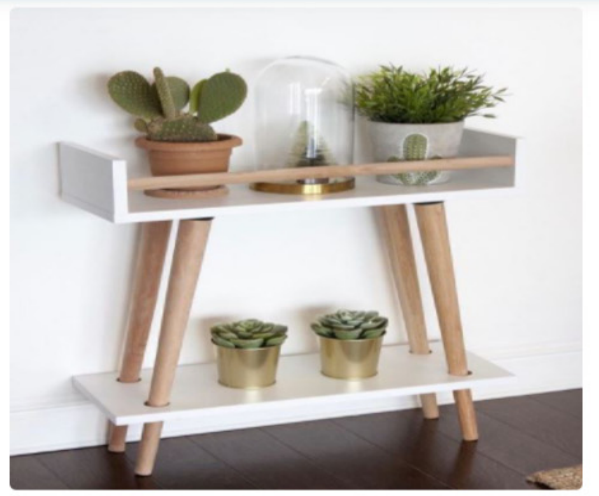

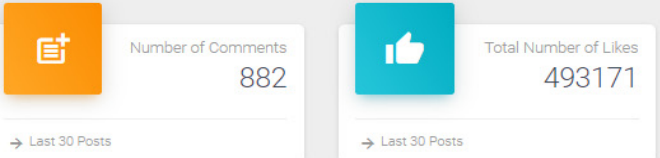

$\rightarrow$ Last 30 Posts

Most Common Words in Comments

iade

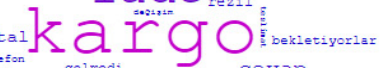

tescơumự

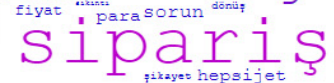

$\infty$

\section{표 Word Usage Numbers}

The 11 Most Used Words

\begin{tabular}{lc} 
Words & Frequency \\
\hline ürün & 131 \\
\hline kargo & 126 \\
\hline siparį & 121 \\
\hline teslim & 84 \\
\hline gün & 79 \\
\hline lade & 77 \\
\hline çüzüm & 51 \\
\hline cevap & 39 \\
\hline sorun & 35 \\
\hline hepsijet & 32 \\
\hline iptal & 32 \\
\hline
\end{tabular}

ptal

틀ost Commented Photo

691 Comments

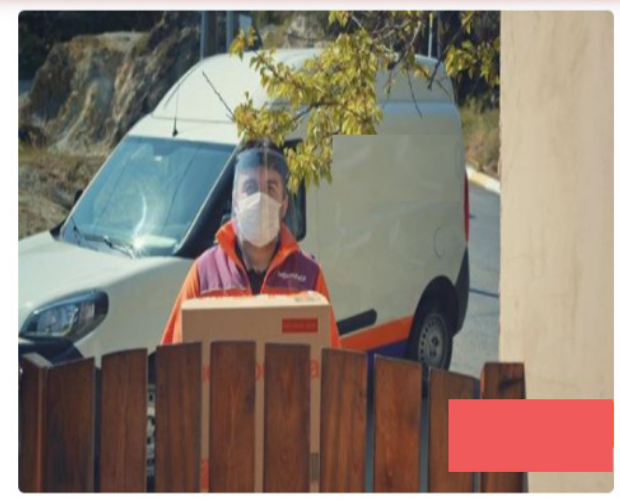

Figure 4. Application interface for X Company. 


\subsection{Marketing Suggestion}

On the "Marketing Suggestion" page, the second section, the most liked sneakers, bags and watches of five leading brands selected for each category were presented to the manager. The marketing suggestion page has been developed to offer marketing suggestions to e-commerce companies, unlike other pages. The main purpose of this page is to reveal the most popular products of the identified big brands on Instagram and to enable e-commerce companies to follow policies regarding those products and products with similar designs. By analyzing these products, e-commerce companies can make various campaigns, discounts, advertisements and reach more sales values by focusing on products similar to these products in determining the product range they will sell. This page will be able to contribute not only to e-commerce companies, but also to stores affiliated with these companies, and even companies that sell these products at retail or supply products from abroad. Interface of the marketing suggestion page is shown in Figure 5.
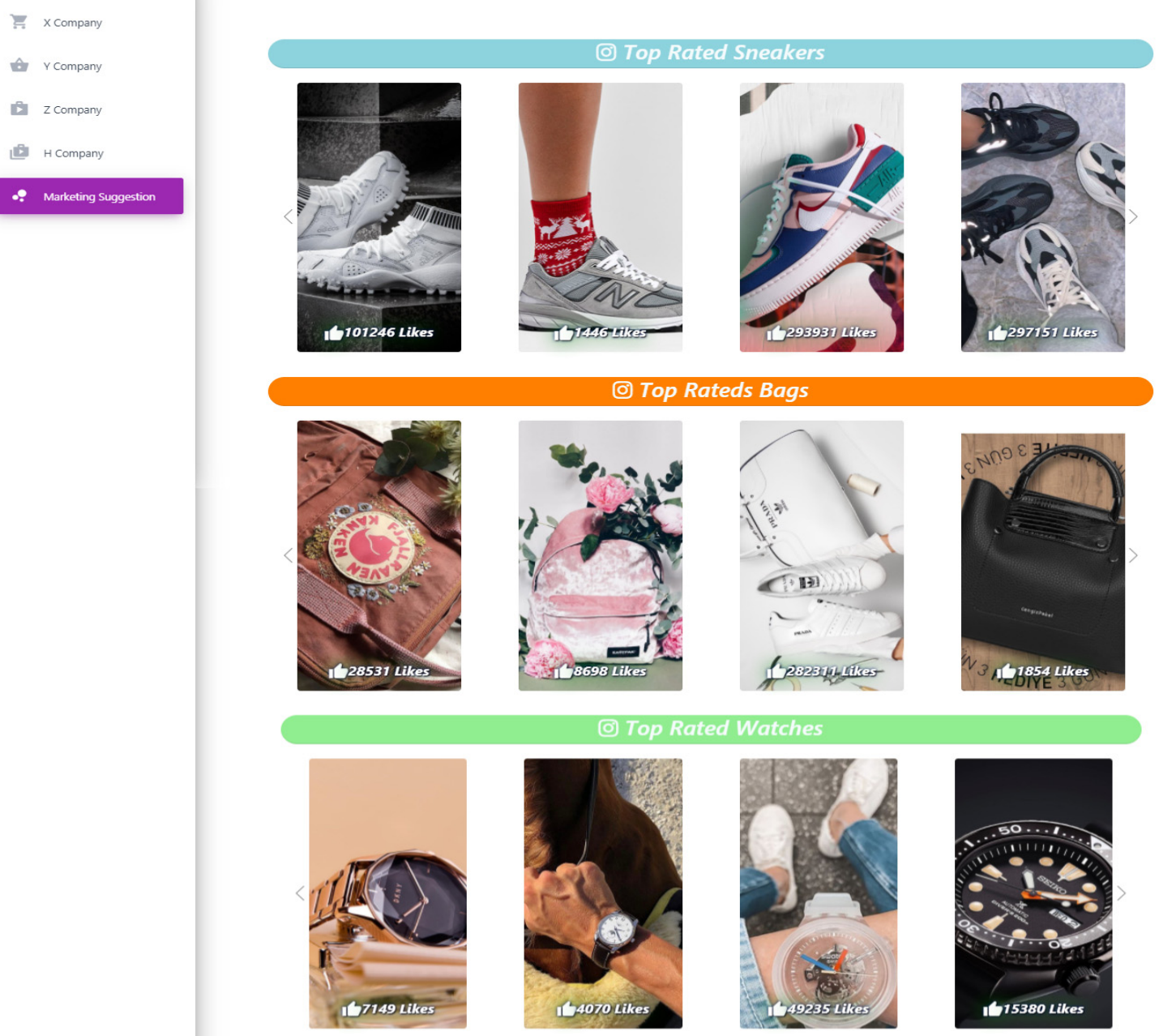

Figure 5. Interface of marketing suggestion page.

\section{Discussion}

Today, the use of social media has become quite common and it has become inevitable that social media analysis will be included in processes such as customer relations management, especially for organizations that sell without a physical store such as e-commerce companies. It is thought that a web application developed with social media data 
will benefit companies' decision-making processes. In this context, Instagram data of four major e-commerce companies selected within the scope of the study were obtained and a web application was developed with analyzes that could be useful to companies. In addition, a section called 'marketing suggestion' has been added to this web application and it is aimed to support companies in terms of marketing.

Many analyses were included in the web application, and the goal was to clearly state the customers' feelings and opinions, the agenda issues and their company expectations. It was desired that the web application be able to report the customer's expectations or complaints to the manager in the most optimal way with data, figures, and tables. In addition to simplicity and comprehensibility, easy usability has also been prioritized in the design of the application.

With the application, decision makers will have the opportunity to understand the feelings and thoughts of the customers in a very short time and have the opportunity to easily access hidden information that is normally impossible to see at first glance. Although it is not possible for companies with millions of followers to pay attention, among thousands of comments, to the problems or suggestions of all their customers, the most used words and even the most supported messages can be shown thanks to this system. While this will improve the efficiency of the management process for customer relationships, it will also save time and ease of use.

The application contains the data of many companies. This can make a great contribution to companies' benchmarking process. Competitors in the same sector have the opportunity to generate a competitive advantage by analyzing the reactions and expectations of each other's customers. The application, which also allows comparison with competitors, aims to support decision-makers in this sense. Companies will be able to make various comments from the visualized data on the application and also use social media data to determine company policies.

In future studies, developing an application by extracting data not only from Instagram, but also from other social media platforms, and developing an expert system that provides not only visualized graphics but also advice to the manager with predictive analysis will make greater contributions to the decision-making process. In addition, by making the same analysis with the data collected from other social media platforms, it can be discussed whether customers give similar reactions on different social media platforms, and which social media platform data will be used in the customer relationship management process will provide maximum benefit. In addition to all of these, the scope of the study can be extended by adding new companies to the existing system developed by selecting four companies.

Funding: This research received no external funding.

Conflicts of Interest: The authors declare no conflict of interest.

\section{References}

1. Agrawal, D.; Bernstein, P.; Bertino, E.; Davidson, S.; Dayal, U.; Franklin, M.; Dayal, M.; Franklin, J.; Gehrke, L.; Jagadish, H.V. Challenges and opportunities with big data. A community white paper developed by leading researchers across the United States. Comput. Res. Assoc. 2012, 5, 34-43.

2. Lin, X.; Li, Y.; Wang, X. Social commerce research: Definition, research themes and the trends. Int. J. Inf. Manag. 2017, 37, 190201.

3. Tian, Y.; Galery, T.; Dulcinati, G.; Molimpakis, E.; Sun, C. Facebook sentiment: Reactions and emojis. In Proceedings of the Fifth International Workshop on Natural Language Processing for Social Media, Valencia, Spain, 3 April 2017; pp. 11-16.

4. Chen, Y.; Yuan, J.; You, Q.; Luo, J. Twitter sentiment analysis via bi-sense emoji embedding and attention-based LSTM. In Proceedings of the 26th ACM international conference on Multimedia, Seoul, Korea, 26 October 2018; pp. 117-125.

5. Akın, B.; Şimşek, U.T.G. Sosyal Medya Analitiği ile Değer Yaratma: Duygu Analizi ile Geleceğe Yönelim. Mehmet Akif Ersoy Üniversitesi İktisadi Ve İdari Bilimler Fakültesi Derg. 2018, 5, 797-811.

6. He, W.; Zha, S.; Li, L. Social media competitive analysis and text mining: A case study in the pizza industry. Int. J. Inf. Manag. 2013, 33, 464-472. 
7. Ghiassi, M.; Skinner, J.; Zimbra, D. Twitter brand sentiment analysis: A hybrid system using n-gram analysis and dynamic artificial neural network. Expert Syst. Appl. 2013, 40, 6266-6282.

8. Wolny, W. Emotion analysis of twitter data that use emoticons and emoji ideograms. In Information Systems Development: Complexity in Information Systems Development-Proceedings of the 25th International Conference on Information Systems Development, Katowice, Poland, 24-26 August 2016.

9. Xu, X.; Wang, X.; Li, Y.; Haghighi, M. Business intelligence in online customer textual reviews: Understanding consumer perceptions and influential factors. Int. J. Inf. Manag. 2017, 37, 673-683.

10. Trivedi, P.; Sharma, A. A comparative study between iterative waterfall and incremental software development life cycle model for optimizing the resources using computer simulation. In Proceedings of the 2013 2nd International Conference on Information Management in the Knowledge Economy, Chandigarh, India, 19-20 December 2013; pp. 188-194.

11. Bassil, Y. A simulation model for the waterfall software development life cycle. arXiv 2012, arXiv:1205.6904.

12. We Are Social. Available online: https://wearesocial.com/digital-2020 (accessed on 9 September 2020). 